\title{
Synthesis of the 10th ICSR conference: innovation in the exploitation and management of shellfish resources
}

\author{
Aad C. Smaal · Jeroen W. M. Wijsman
}

Published online: 6 August 2009

(C) The Author(s) 2009. This article is published with open access at Springerlink.com

Sustainable exploitation and management of shellfish populations is an important issue for stakeholder groups such as shellfish industry, nature conservation NGO's and governments. Shellfish culture depends in many cases on natural processes and it often occurs in protected coastal areas, that are also under high pressure by other human activities. Uncertainty in resource availability (recruitment, algal production and quality, space) puts pressure on the industry and asks for sustainable innovations in resource exploitation. For environmental protection, knowledge is required of impacts of shellfish exploitation and of successful methods for restoration and improvement of exploitation. Regulation and management of exploited shellfish resources, particularly in nature conservation areas, is a priority issue for governmental institutions as conflicts of interest are manifest. Knowledge is required of technological and management innovations to contribute to solutions and create new opportunities. These issues have been addressed during the conference in a series of parallel sessions. Session chairs (names in brackets) compiled a comprehensive review of actual research issues that were presented during the sessions. The presentations are summarized in this conference synthesis.

For the topic on recruitment (Luca van Duren and Karsten Reise) the primary statement is that the combination of invasive species and climate change launched a revolutionary turnover in coastal shellfish communities. New species profit from changes in climate conditions while existing species suffer from it. Major research topics should focus on the various types of feedback under field conditions: positive when adults provide habitat or substrate for (gregarious) settlement, negative in terms of adult filtration of larvae. More knowledge is needed on secondary migration and settlement, dispersal potential of larvae and loss through flushing. There is a need for practical knowledge to improve spat collection and survival, in order to achieve sustainable exploitation and reduce benthic seed fishery.

\footnotetext{
A. C. Smaal $(\bowtie)$

Aquaculture, Imares, P.O. Box 77, 4400 AB Yerseke, The Netherlands e-mail: aad.smaal@wur.nl

J. W. M. Wijsman

Ecology, Imares, P.O. Box 77, 4400 AB Yerseke, The Netherlands
} 
Spat production was also discussed during the session on innovation in hatchery/nursery systems (Pauline Kamermans and Rene Robert). Promising results on new formulated feeds for mussel hatchery and nursery phases were presented. The importance of parent feeding for larval development and settling was demonstrated. More knowledge on larval physiology and food requirements is needed. It was demonstrated that the production of algal cultures could be improved by new generation photobioreactors. Reduction of mortality in the early stages is a crucial factor for successful application of hatchery/nursery systems. Genetic improvement through selective breeding can profit from new tools. This topic was discussed in more detail in the genetics and genomics session (Pierre Boudry and Jose Fuentes).

For the role of shellfish in the food chain (Peter Herman and Ovind Strand), it was concluded that measuring physiological rates still needs to be improved. New techniques applying in situ tracers are promising for food web studies, that are important in addressing top-down or bottom-up control mechanisms. Attention is needed for the scaling of the role of shellfish: from local to ecosystem level.

The carrying capacity (Theo Prins and Marianne Alluno-Bruscia) topic focused on modeling and there were quite some papers about the applications of Dynamic Energy Budget (DEB) models for shellfish growth and development. Much of the work that was presented results from the Aqua DEB project. Attention was given to the possibilities of using remote sensing techniques information for addressing food availability in marine systems. Also new techniques for 3D scanning of food availability in bays were demonstrated.

In a related session on eutrophication and harmful algal blooms (Sandy Shumway) it was concluded that these type of problems require integrated coastal zone management, as management decisions need to be taken to deal with these problems, rather than technical solutions.

The topic on Chances for offshore culture (Bela Buck and Muki Spighel) showed that this field develops rapidly. This is triggered by the lower human and nature conservation pressures in this region compared to the coastal systems. Various opportunities were demonstrated and offshore mussel culture is now in practice in for example New Zealand.

In the session on the impact of invasions (Jeroen Wijsman and Norbert Dankers) a number of case studies showed invasion strategies and vectors. It is recommended to carry out a risk analysis before transplantations are allowed. Research questions deal with the role of invaders in altering the functioning of the ecosystem. Also more knowledge is required on the drivers and the qualities that make some species more successful invaders in a specific environment than others.

Next to invasions there was a theme session on shellfish restoration (Dorothy Leonard and Rick Devoe). Some of the major recommendations are to enhance what's there by using hatchery-bred native species and to replace what is not. This requires studies to access the feasibility and potential risks of introducing non-native species. Is was shown that the recovery of natural populations in general requires high density stocks to act as broodstock. Finally it was stated that "one's treasure is another's trash", by which they mean that the introduction of a non-native species to a new region may be undesirable, even when this species was successful in another region.

The impact of shellfish culture was addressed in the benthic impact session (Christian Hily and Per Dolmer). Various case studies showed different types of effects. Impacts on benthic fauna are highly variable between locations and related to hydrodynamics of the system. Various monitoring parameters to quantify the impacts were recommended. The impacts can also be positive, and the strategy was discussed on minimization of impacts 
and optimization by supporting additional populations if possible. Therefore, it was recommended to develop adaptive management for off bottom shellfish culture.

In the session on education and extension programs (Gavin Burnell and Wilbert Schermer Voest) some examples of shellfish restoration and education programs were presented. It was concluded that, especially in North America, shellfish restoration is a tool that is often successfully used to get engagement and more understanding with marine environment in the society, particularly with the use of volunteers for projects. This tool might also be applied in Europe and other continents around the world.

In a session on energy for shellfish culture (Willem Brandenburg) the relation was addressed between algal culture for shellfish and the use of algae for biofuels. It was concluded that plant production in the marine environment will be the base for IMTA at sea and inland production systems. Therefore basic understanding is needed of algae in terms of productivity. High efficiency photo bioreactors are promising, but further development should be focused on cost reduction.

Nature conservation and stakeholder involvement (Hein Sas and Han Lindeboom) was addressed by a number of case study presentations. Is was shown that global overviews are needed on the fate of native shellfish stocks. This topic is addressed by the shellfish at risk initiative of The Nature Conservancy. The causes behind the decreases of the native stocks are often clear, but also often mysterious (invasive species, eutrophication, ...). Therefore, study is needed to unravel multi-factors behind the observed decreases. In general the restoration attempts are mostly just starting, using widely varying approaches. The main question that arises is: What are critical failure and success factors? The approach and attitude of restoration projects are very much culture dependent and the successes are incidental. The success or failure factors for stakeholder involvement need to be addressed.

\section{Conclusions}

The link between shellfish culture and shellfish restoration was addressed in many ways during the conference. Close relationships were demonstrated between exploitation, management and conservation. Understanding the role of shellfish and shellfish culture in the ecosystem is considered as a fundamental basis for sustainable management focused on protection, restoration and exploitation. Innovations in cultivation techniques, cultivation systems, as well as management systems should lead to an exploitation that potentially contributes to both economic and ecological management goals, i.e. to sustainable shellfish (eco)systems.

Open Access This article is distributed under the terms of the Creative Commons Attribution Noncommercial License which permits any noncommercial use, distribution, and reproduction in any medium, provided the original author(s) and source are credited. 